\title{
SUBTRAÇÃO DE VOLUMES EM ATERROS SANITÁRIOS: GESTÃO DOS RESIÍDUOS DE PODA DE ÁRVORES URBANAS
}

\author{
Barbara Lucia Guimarães Alves ${ }^{1}$, \\ ${ }^{1}$ D.ra em Psicossociologia de Comunidades e Ecologia Social pela Universidade Federal do Rio de Janeiro (2020); Msc. em \\ Engenharia Ambiental pela Universidade do Estado do Rio de Janeiro, Brasil (2007), barbaraalves@globo.com
}

RESUMO: A pesquisa possibilitou um olhar sobre a questão de excesso de resíduos de podas de árvores urbanas remetido aos aterros sanitários. Assim, teve como objetivo desenvolver um modelo de gerenciamento para os resíduos de poda de árvores visando a sua utilização, com a possibilidade de minimizá-los na disposição final. A metodologia baseou-se na criação um modelo diferenciado do ponto de vista legal, gerencial, tecnológico e econômico, que pudesse servir de base à pesquisa e gerar estratégias para beneficiar o meio ambiente. Foi feita uma apreciação no Centro de Tratamento de Resíduos Sólidos de Gericinó, para a qual foi elaborada a proposta de criação de uma Usina Verde nas áreas já desativadas do aterro, visando a sua revitalização. Esta ação contemplaria a região com um bosque, onde seriam absorvidos os subprodutos dos resíduos de poda. Haveria, também, a probabilidade de destinação certa, para a composição do mobiliário urbano da cidade, cuja ação poderia privilegiar a capacidade operacional dos catadores nas etapas de obtenção de compostos orgânicos e partes de plantas.

PALAVRAS-CHAVE: Árvores, resíduos e gerenciamento.

ABSTRACT: The research made it possible to look at the issue of excess waste from urban tree pruning sent to landfills. Thus, it aimed to develop a management model for tree pruning waste with a view to its use, with the possibility of minimizing it in the final disposal. The methodology was based on the creation of a different model from a legal, managerial, technological and economic point of view, which could serve as a basis for research and generate strategies to benefit the environment. An appraisal was made at the Gericinó Solid Waste Treatment Center, for which the proposal for the creation of a Green Plant in the deactivated areas of the landfill was prepared, aiming at its revitalization. This action would contemplate the region with a forest, where the byproducts of the pruning residues would be absorbed. There would also be a likelihood of a correct destination for the composition of the city's urban furniture, whose action could favor the pickers' operational capacity in the stages of obtaining organic compounds and plant parts.

KEYWORDS: Trees, residues and management. 


\section{INTRODUÇÃo}

A geração de resíduos através dos tempos vem se tornando cada vez mais significativa (Sisinno \& Oliveira, 2000), em função do aumento populacional mundial e do crescimento constante dos padrões de consumo. No Brasil, segundo a Associação Brasileira de Empresa de Limpeza Pública e Resíduos Especiais (ABRELPE) (2014), a geração de resíduos sólidos urbanos em 2014 foi de aproximadamente 78,6 milhões de toneladas, o que representa um aumento de $2,9 \%$ de um ano para outro, índice superior à taxa de crescimento populacional no país no período, que foi de $0,9 \%$ nos dados de geração anual e per capita em 2014, comparados com 2013. Em virtude de tal realidade, propostas de gerenciamento têm sido efetivadas na intenção de solucionar as mazelas ambientais decorrentes desses conflitos.

Medidas compensatórias no contexto do paisagismo urbano podem ajudar a reverter esse processo. Estratégias podem ser criadas no sentido de equilibrar as áreas edificadas e áreas arborizadas, gerando, dessa forma, um conforto ambiental. Segundo Laera (2006), na cidade do Rio de Janeiro, a arborização urbana constitui um dos componentes principais do paisagismo carioca e compõe um estreitamento entre elementos naturais fitogeográficos e elementos da malha urbana, influindo, decididamente, na qualidade de vida da população, bem como no traçado paisagístico da cidade. Os serviços ambientais, como a arborização urbana, influenciam o bem-estar dos indivíduos, apresentando-se na mesma proporção que os bens materiais. Porém, os resíduos provenientes de intervenções nas árvores de uma cidade, carecem de ações que as possam conjugar com novas tecnologias de aproveitamento. Sabe-se, que o manejo do arvoredo urbano é fundamental e imprescindível para a boa disposição dos elementos paisagísticos das vias urbanas.

Pode-se afirmar que o estudo está particularizado para a questão da gestão dos resíduos de poda, dando ênfase a subutilização econômica de seus resíduos, como forma de redução na fonte, no sentido de viabilizar o tempo de vida dos aterros sanitários e/ou controlados, fazendo com que propostas como essas sejam uma prerrogativa para se melhorar a qualidade ambiental de acordo com Eigenheer, Ferreira e Adler (2005).

Dentro dessa perspectiva, suscita-se a necessidade de uma abordagem legal, gerencial, tecnológica e econômica que sirva de base de conhecimento, para alicerçar as possíveis probabilidades do estudo.

Faz-se necessário, também, um entendimento em torno dos conflitos na arborização pública, para que sejam mais bem administrados. De igual importância, é o conhecimento dos diferentes métodos de valoração de árvores urbanas, no sentido de se fazerem compreender os valores embutidos nos resíduos de poda. Da mesma forma, serão observados os critérios estabelecidos para a disposição final dos resíduos, com enfoque particularizado no Estudo de Caso referente à Fundação Parques e Jardins - Subgerência de Hortos da Diretoria de Arborização e Produção Vegetal (Unidade Taquara, Rio de Janeiro), a qual exerce o manejo do arvoredo urbano nos bairros da Barra da Tijuca e Jacarepaguá (Alves, 2007). Nesse ínterim, será dada uma atenção prioritária ao Centro de Tratamento de Resíduos Sólidos de Gericinó, pelo fato do aterro recepcionar grande parte dos resíduos da área que se pretende estudar. As condições necessárias para a implantação de um sistema de reaproveitamento de resíduos de podas de árvores de domínio público devem ser avaliadas, ressaltandose as espécies mais podadas e a utilização do material proveniente das mesmas.

\section{GESTÃO NA FONTE DOS RESÍDUOS DE PODA DE ÁRVORES}

Devem-se concentrar esforços no sentido de priorizar as ações de gestão de resíduos na sua fonte geradora. Deve-se considerar que o procedimento ocorra imediatamente após a retirada da galhada das vias públicas. Em relação ao arvoredo urbano, esta ação torna-se difícil, devido às características das cidades. Seria viável, de acordo com critérios técnicos, a coleta prévia de sementes antes da indicação para poda ou remoção de árvores, quando necessárias, com a finalidade de aproveitamento e objetivando a criação de um banco de sementes por parte da Fundação Parques e Jardins do Rio de Janeiro e/ou de seus credenciados.

\section{VALORIZAÇÃO DE RESÍDUOS DE PODA URBANA}

Embora seja difícil uma abordagem sobre a valorização de resíduos oriundos das árvores urbanas, Bidone (2001) ressalta a importância da redução de resíduos na origem, ação que requer modificação ou substituição em processos e equipamentos de produção e de materiais, e alteração de hábitos em decorrência dessas mudanças. A reciclagem garante o retorno desse material ao sistema produtivo como matéria prima. Segundo Bidone (2001), a compostagem, entendida como a confecção de compostos orgânicos a partir de resíduos para utilização na agricultura. Quaisquer que sejam as metodologias aplicadas a esses materiais, estarão em evidência os aspectos ambientais e financeiros, traduzindo-se em respostas positivas. É importante salientar, neste estudo, a preponderância da utilização de materiais vegetais de menor diâmetro, usados para compostagem, em detrimento daqueles
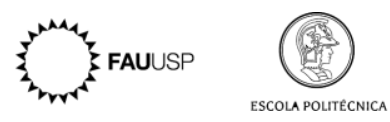
de diâmetro maior, economicamente menos explorado. Quanto às madeiras de bitola maior, não têm sido elaborados muitos trabalhos científicos acerca de seu aproveitamento, tornando-se alvo de trabalhos artesanais com alguma utilização paisagística, ou ainda subutilizadas como elementos decorativos. Destarte, reduzindo volumes consideráveis na sua destinação final. Esse material, também, pode se transformar em lenha, servindo como combustível ou como moeda de troca em olarias. É uma realidade a utilização de madeiras para formação de carvão, que, por vezes, não ocorre dentro da ilegalidade, carecendo de ações por parte do Poder Público (Alves, 2007). Outras utilidades podem ser atribuídas aos resíduos, em especial as partes de plantas.

\section{SUBUTILIZAÇÃO DE PARTES DE PLANTAS A PARTIR DE RESÍDUOS DE PODAS URBANAS}

A grande variedade de madeiras obtidas, nos serviços de poda realizadas pela Fundação Parques e Jardins no município do Rio de Janeiro, é um indício da necessidade de um estudo detalhado, no sentido de que possam ocorrer, em um futuro próximo, medidas que possibilitem a segregação de diferentes tipos de resíduos, de acordo com as diversas possibilidades de reaproveitamento e destinação a serem realizadas $A$ gama de utilidades referentes a esse material é significativa. O potencial energético é indiscutível, a existência de madeiras nobres é real para diversos usos. As madeiras mais macias se prestam à fabricação de muitos utensílios utilizados pela população. A serragem é prensada, de forma à obtenção de toletes, para queima em fornos.

Uma vez realizado o mapeamento de espécies por região, pode-se traçar um planejamento com as possíveis tendências de utilização por espécies. Este procedimento vem ao encontro das necessidades de redução de material orgânico largamente disponibilizado para os aterros sanitário ou controlados e, até mesmo, para lixões. Essa seria uma medida que beneficiaria a vida útil dos mesmos (Sisinno \& Oliveira, 2000). No Rio de Janeiro, os aterros controlados de Gramacho e de Gericinó, que já estão tecnicamente extintos, ainda perduram com suas atividades.

A Prefeitura, de acordo com o Plano Municipal de Gestão Integrada de Resíduos Sólidos do Rio de Janeiro (Prefeitura da Cidade do Rio de Janeiro, 2012), buscando identificar alternativa de destinação para resíduos de poda do arvoredo urbano, da ordem de $40 \mathrm{t} / \mathrm{dia}$, constituído de material volumoso de difícil compactação e de características de decomposição diferenciada, estão sendo estudadas, em parceria com empresas do ramo, alternativas técnicas e ambientalmente viáveis para o seu reaproveitamento. Evitando o encaminhamento para disposição em aterros, garantindo o aumento de sua vida útil, fomentando o aproveitamento de resíduos como fonte energética ou como insumo para a produção de compostos orgânicos para fins agrícolas e paisagísticos. E, ainda, estabeleceu metas para garantir que os resíduos gerados nas atividades de podas da arborização municipal para que tivessem destinação ambientalmente adequada em 50\% dos resíduos gerados até 2016 e em 100\% até o final de 2020. A ênfase seria na compostagem, aproveitamento energético, desde que identificada a alternativa técnica, econômica e ambientalmente sustentável (Prefeitura da Cidade do Rio de Janeiro, 2012).

Obviamente, a proposta do estudo pressupõe novas problemáticas. Uma das mais consistentes diz respeito à disponibilidade de área para segregação de materiais e consequente armazenagem dos mesmos. Do ponto de vista econômico, sugere-se a implantação de sistema monetário que possibilite a retirada de parcelas podadas, por empresas interessadas, que possam reverter através de medidas compensatórias, a exemplo do já ocorre em relação ao Habite-se, o valor das mudas, de tal forma a originar recursos para implantação de tais áreas (Alves, 2007).

Acena-se para a possibilidade, também, de um plantio programado, priorizando-se a formação de mudas para diferentes destinações (Sanders, 1984), no sentido de reduzir ilhas de calor, recompor a mata ciliar, cinturões verdes para aterros sanitários, programação para baixadas - visando redução de alagamentos, proteção de encostas, reuso de águas residuais, criação de barreiras limítrofes nas áreas de conservação, entre outros (Alves, 2007). Pode-se exemplificar, de acordo com Laprovitera (2005), em seu estudo sobre Aproveitamento de Resíduos de Poda e da remoção de Árvores de Domínio Público na Cidade do Rio de Janeiro. O autor propõe conforme o experimento realizado no Centro de Tratamento de Resíduos do Caju - RJ, que seja feita uma triagem dos resíduos provenientes de podas, determinando seis classes distintas, a saber: ramos finos e folhagem; lenha de pequena bitola - diâmetro máximo de cinco $\mathrm{cm}$; lenha de média bitola - diâmetro de 5 a $10 \mathrm{~cm}$; toras de bitola inferior - diâmetro de 10 a $20 \mathrm{~cm}$; acima de $20 \mathrm{~cm}$ e raizeiros. Privilegiando, dessa forma, que os materiais não somente possam ser subutilizados para compostagem, apontando, assim, outras pistas para o aproveitamento de resíduos de poda de árvores de acordo com as Figuras 1-2, interferindo na paisagem urbana e também no social, posto que as pessoas se beneficiem desse mobiliário.

Interessante é que as práticas se conjuguem, tendo uma utilização maior dos subprodutos de poda, através do composto, da adubação verde ou do uso do biodigestor. 

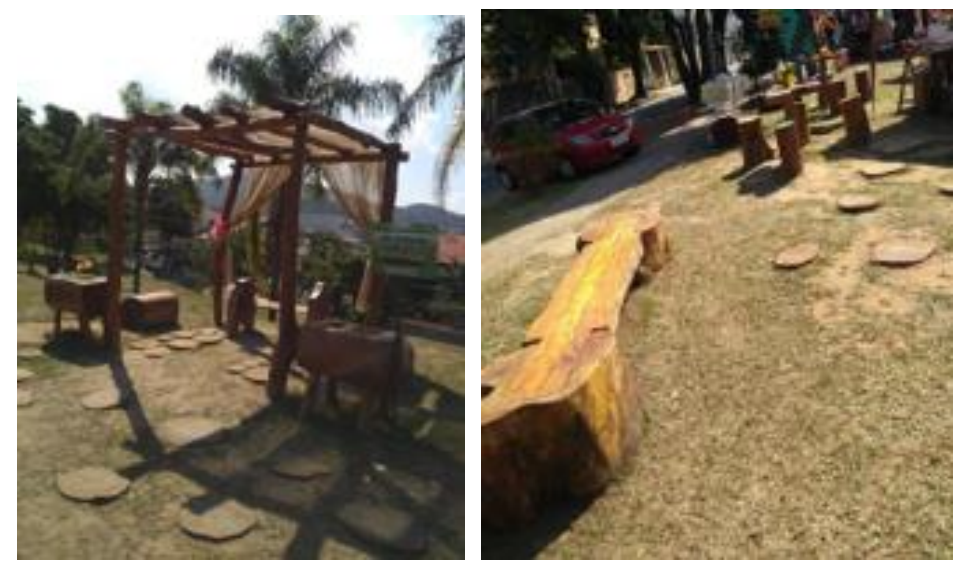

Figuras 1 e 2: Elementos paisagísticos na Praça Candido da Silva Mendes, Taquara, Rio de Janeiro

Nesse contexto, observou-se a Administração Pública centrada e descentralizada (Madeira,2003), a partir disso, foi elaborado um fluxograma que evidencia uma concepção para o reaproveitamento de resíduos de poda com base na estrutura administrativa da Cidade do Rio de Janeiro (Figura 3).

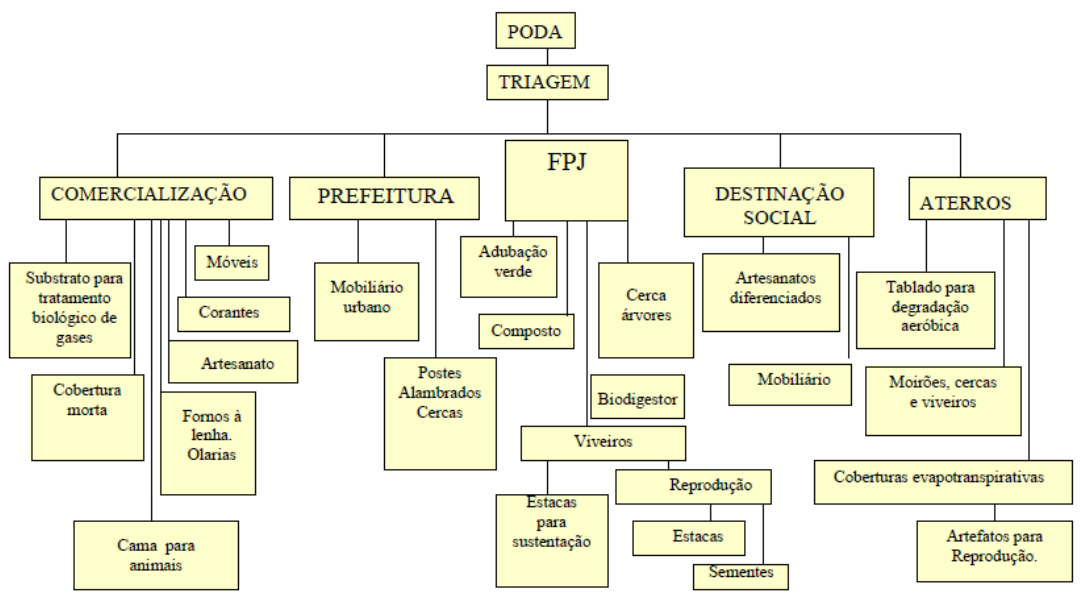

Figura 3: Fluxograma de concepção de reaproveitamento

O Fluxograma delineado acima traça uma concepção de reaproveitamento baseada na estrutura da Cidade do Rio de janeiro, porém há possibilidades de adaptação para outras cidades (Alves, 2007).

\section{ESTUDO NA FUNDAÇÃO PARQUES E JARDINS DA CIDADE DO RIO DE JANEIRO}

Num primeiro segmento, foram elaboradas propostas de segregação diferenciadas em: em sementes, para reprodução; folhas e galhos de menores diâmetros destinados à trituração e posterior compostagem; escolha de partes para reprodução; material de maior diâmetro, para os quais se sugere separação em seis classes de bitolas distintas para aplicações diversas (Baratta, 2007).
Sugeriu-se também a elaboração de uma matriz com diferentes formas de aproveitamento econômico das árvores, com base em um estudo elaborado por Baratta (2007). Foram selecionadas trinta e duas espécies arbóreas, das quais se destacaram doze, com maior representatividade em volume de poda. Essa seleção permitiu que se criasse uma matriz com diferentes formas de aproveitamento por espécies. (Tabela 1). A pesquisa foi realizada com base em uma seleção de árvores no domínio da Fundação Parques e Jardins do Rio de Janeiro, com base nas anotações técnicas de Lorenzi $(1993,2003)$

O município do Rio de Janeiro é dividido geograficamente, o estudo refere-se a Áreas de Planejamento 4. Feita essa observação, pode-se depreender o como poderia ser o aproveitamento 
residual referente às espécies mais expressivas da região em foco.

Tabela 1 - Aproveitamento econômico por espécies

Fonte: Elaboração da autora

A utilização econômico-ecológica foi elaborada de acordo com as características das madeiras das árvores da região.

\section{ELABORAÇÃO DE PLANO DE GESTÃO INTEGRADA}

Para dar a destinação para cada material oriundo da poda de árvores, selecionaram-se alguns dos entes municipais da Cidade do Rio de Janeiro, mais propícios ao aproveitamento em ações integradas, em busca de eficiência (Alves, 2007). O plano de gestão é de fácil elaboração a partir do modelo, podendo-se dessa forma, aplica-lo à outras municipalidades, conforme fluxograma a seguir (Figura 4).

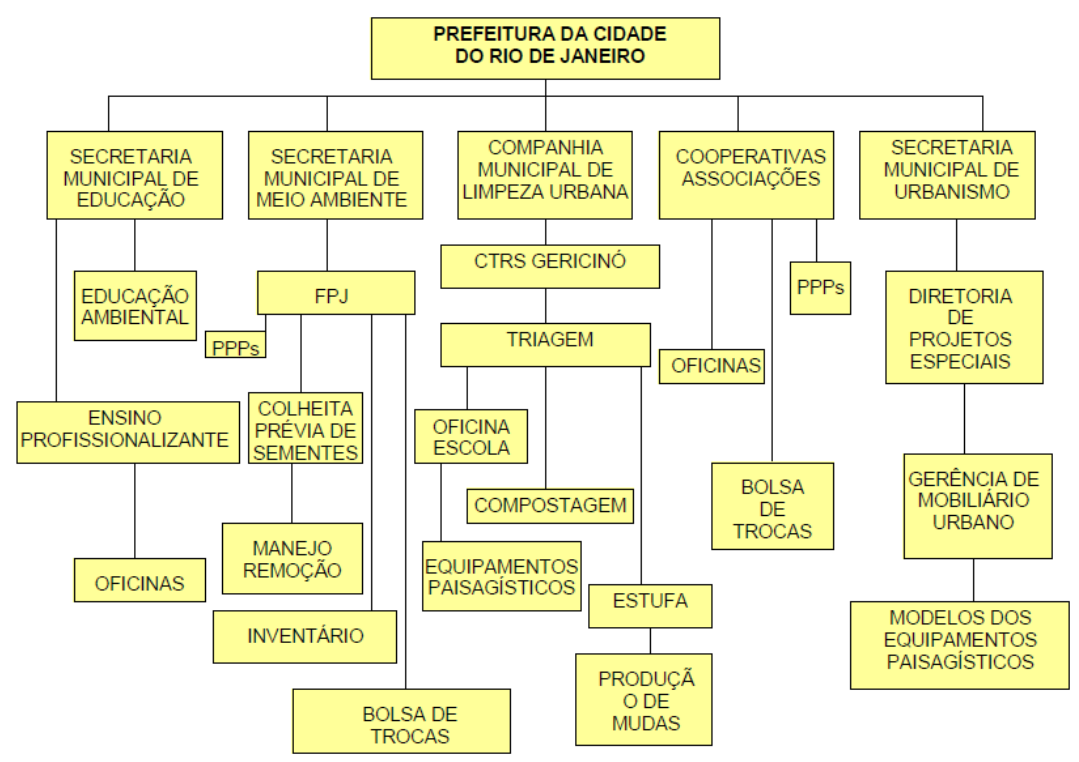

Figura 4: Plano de gestão integrada

Diante das possibilidades apresentadas, se poderia fazer uma modelagem para o aproveitamento dos resíduos de poda de árvores urbanas?

\section{MODELO DE APROVEITAMENTO EFICIENTE DOS RESÍDUOS DE PODAS DE ÀRVORES URBANAS}

O modelo abaixo corresponde ao Modelo Eficiente de Aproveitamento dos Resíduos de Poda de Árvores Urbanas (Figura 5), visando alcançar eficiência pela destinação correta dos subprodutos provenientes da poda de árvores. Foram especuladas todas as possibilidades de aproveitamento, supondose, para tal, que se crie uma estrutura no aterro receptor. Inclui-se uma proposta paralela para o local para onde serão destinados, entre os quais sugerimos a estruturação de um galpão - que poderá utilizar resíduos de construção civil - para segregação e elaboração de materiais pertinentes à proposta. Para tanto se pressupõe total integração com os entes municipais. Vislumbra-se a criação de oficinas de trabalho para os catadores, minimizando fatores como sofrimento, desigualdade, alienação, promovendo uma identidade cultural, portanto, sua inclusão social (Alves, 2007). Partindo-se da premissa de acordo com Moscovici (2011) que o trabalho digno interage com a identidade do indivíduo em sua função social e com a sua sobrevivência. 


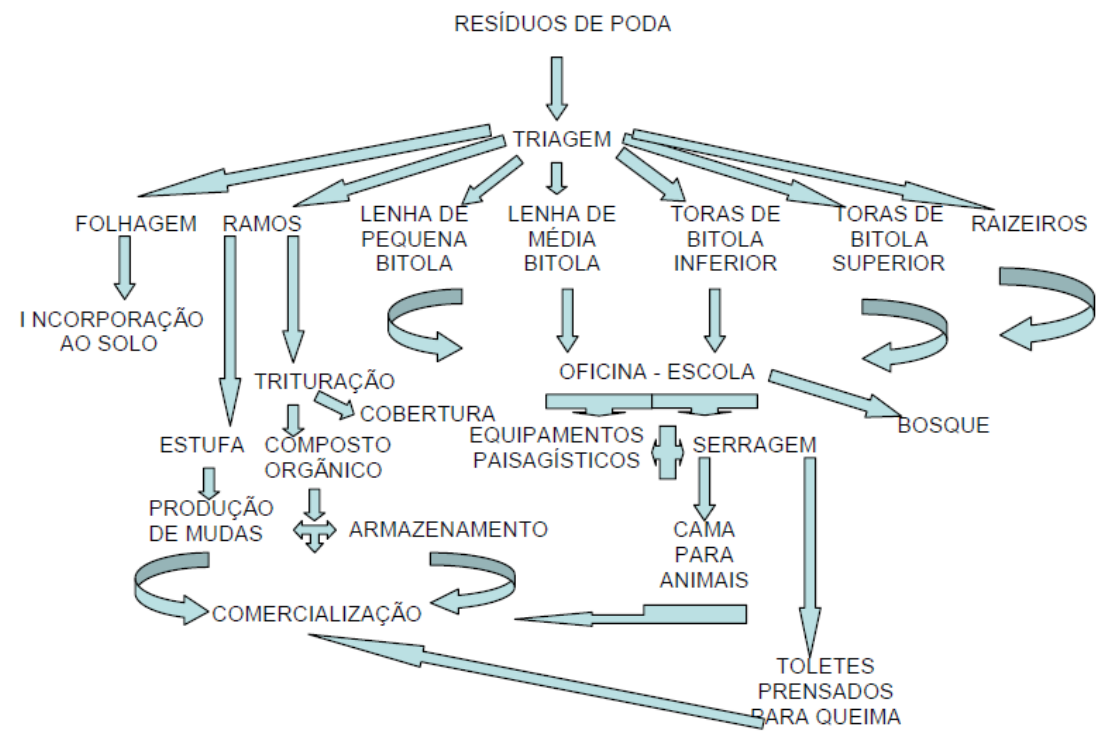

Figura 5: Modelo Eficiente de Aproveitamento dos Resíduos de Poda de Árvores Urbanas

Posteriormente ao encerramento de atividade nos mesmos, propõe-se a formação de um bosque, devido às características de instabilidade do terreno pós encerramento de atividades nos aterros sanitários e similares. Suscita-se, a partir do modelo elaborado (Figura 5), a construção de um pátio para a segregação da galhada e de dois galpões a serem construídos em aterros sanitários. Desses, um destinado a uma oficina-escola, e outro para abrigar o maquinário e o ferramental para a obtenção do composto orgânico. O pátio para triagem deverá comportar as classes distintas de segregação de árvores estabelecidas por Laprovitera (2005) prevendo-se espaços para estocagem de do material triturado, uma área para o peneiramento, e outra para o ensacamento do composto orgânico obtido. Propõe-se a construção de uma estufa agregada ao bosque em composição, com a função de abrigar as mudas obtidas por reprodução sexuada, por sementes e reprodução assexuada por partes de plantas (Alves, 2007). Para outras atividades seriam necessários equipamentos - trituradores, peneiras, motosserras, machados, carrinhos adaptados para carregamento dos troncos, tesouras de poda e um micro trator com carreta. Além daqueles destinados às atividades de marcenaria, serras tico-tico, serras circulares, lixadeiras, furadeiras, entre outros. Seria importante a disponibilização uma autoclave, destinada à imunização de madeiras. Em função de apoio humano/ logístico, sugere-se, de acordo com Alves (2007) a mão-de-obra dos ex-catadores, quando encerradas as atividades no aterro, resgatando-se a dignidade dos mesmos, gerando um benefício socioambiental.

\section{MATERIAIS E MÉTODOS}

Como diretriz metodológica, com base em Lerner (1992), foi utilizado o método de raciocínio indutivo e se complementou por meio de pesquisas de natureza qualitativa e quantitativa. O foco da pesquisa se concentra no estudo, no qual foi colocado em evidência as condições de alguns municípios do Rio de Janeiro, no que se refere aos resíduos sólidos.

Quanto à abordagem multimetodológica, se baseou na coleta de dados, através de documentação indireta, com pesquisa documental e bibliográfica e através de entrevistas. Constou de questionários mistos (abertos e fechados) para medição de variáveis individuais. As entrevistas e a análise dos dados se procedeu por intermédio de fluxogramas e tabelas.

Quanto ao detalhamento, propôs-se um estudo do contexto social dos trabalhadores, envolvidos na coleta de materiais dispostos nos vazadouros e suas possíveis inclinações para as melhorias propostas. Também foram pesquisadas as espécies arbóreas que têm como características comuns à expressividade em quantidade de material residual, podado no município do Rio de Janeiro, onde foram feitos intervenções no arvoredo urbano, que podem servir de base à proposta. A partir dos resultados pesquisados, foi proposta a realização de uma matriz, cujo objetivo é demonstrar diferentes formas de aproveitamento econômico por espécie, são recolhidas e dispostas em aterros. Para os resíduos de podas, provenientes de árvores urbanas 
demonstraram-se possibilidades e tendências de transformação da destinação final, para todos os componentes das espécies arbóreas. Por intermédio de triagem, segregando-se o material para posterior compostagem (Baratta, 2007) e material de maior diâmetro para os quais se sugere separação em bitolas distintas (Laprovitera, 2005), com intuito de atender as demais utilidades descritas no projeto.

A metodologia se aplica por se basear em pesquisa seletiva de espécies com destino certo, na área de concentração do estudo. Os dados obtidos foram classificados de acordo com a segregação do material.

A interpretação e Análise dos Dados Coletados e Resultados envolveu os dados do material em estudo, a partir de observações feitas através das visitas realizadas, das consultas levadas a efeito pela diagnose desenvolvida no estudo. A pesquisa de caráter social se baseou nas respostas obtidas em entrevistas e questionários, levando-se em consideração a documentação investigada para elaboração de um consenso único das condições estabelecidas para os catadores, bem como das espécies estudadas.

\section{CONCLUSÃO}

Para a organização de políticas públicas supõe-se que deva haver distribuição igualitária de investimentos em infraestrutura. A disponibilização de recursos financeiros, em geral, é insuficiente para a solução de problemas ambientais. A participação conjunta do governo e da sociedade faz-se supostamente necessária. Neste contexto, é importante a interpretação multidisciplinar, envolvendo diferentes variáveis. Destarte, urge a verificação do limite de capacidade dos aterros regionais. Como também, necessita-se de investimentos em atividades para os catadores de resíduos, como medida preventiva após encerramento de atividades nos aterros. Pistas apontam para alternativas que podem priorizar redução de gastos com transporte de materiais residuais e valorização das árvores, que podem estar embutidas nos resíduos de poda. Apesar de limitações pontuais, como: impossibilidade de segregação dos resíduos na fonte e quanto a limitação de mão de obra, para supri-la, sugere-se instruções aos funcionários da administração pública e catadores, gerando gestão participativa e estabilidade socioambiental. Quanto a limitação econômica para manejo nos aterros sanitários em função de iminências de sua extinção, o estudo pode oferecer condições para encerramento de um ciclo de vida útil, uma vez estabelecidas bases no aterro, dispensando a alocação de recursos para o deslocamento de mudas, insumos e mobiliário urbano, para a área a ser revitalizada no próprio local, traduzindo-se em compensação de custos de investimentos através de benefícios a serem obtidos.

O paisagismo urbano pode exercer outras funções no padrão de sustentabilidade de uma cidade. Podendo-se ter um olhar diferenciado das políticas públicas, em relação à diversidade de ações integradas que podem se descortinar.

Quanto à gestão participativa pode-se: optar por retiradas prévias das sementes; conduzir os resíduos de poda para Centros de Tratamento de Resíduos Sólidos; aperfeiçoar as áreas de aterro a partir das propostas do estudo, congregando disponibilidade espacial para destinação final dos resíduos e reaproveitamento dos mesmos. A partir da observação do modelo eficiente de aproveitamento dos resíduos de poda de árvores urbanas, em consonância com a revitalização da área aterrada, pode-se ter como propósito para melhoria do local. A sugestão do estudo aponta para a viabilização da produção de compostos orgânicos e produção de mudas nos aterros, sem gastos com transporte e insumos, para benefícios futuros.

\section{CONSIDERAÇÕES FINAIS}

$O$ estudo aponta para o incentivo de pesquisas para utilização de espécies promissoras em aterros sanitários, para a estimulação de produção de equipamentos paisagísticos e outros mobiliários urbanos, que poderão viabilizar a absorção da mãode-obra dos excitadores. Fechando assim um ciclo, promovendo melhorias socioambientais e econômicas nas localidades degradadas, respeitando e criando condições humanitárias para os atores envolvidos diretamente com as questões dos resíduos.

\section{REFERÊNCIAS}

1. Alves, B. L. G. (2007). Gestão de resíduos de poda: estudo de caso da Fundação Parques $e$ Jardins do Município do Rio de Janeiro (Dissertação de mestrado). Universidade do Estado do Rio de Janeiro, Rio de Janeiro, RJ, Brasil.

2. Associação Brasileira de Empresas de Limpeza Pública e Resíduos Especiais (2014). Panorama. Limpeza Pública e Resíduos Especiais. Recuperado de http://www.abrelpe.org.br/Panorama/panoram a2014.pdf

3. Baratta, A. P., Jr. (2007). Utilização do composto de resíduos da poda da arborização urbana em substratos alternativos para a produção de mudas. (Dissertação de mestrado). Universidade Federal Rural do Rio de Janeiro, Seropédica, RJ, Brasil. 
4. Bidone, F. A. (Org.) (2001). Resíduos sólidos provenientes de coletas especiais: eliminação $e$ valorização. Brasília: FINEP/PROSAB.

5. Cadernos Pedagógicos I, II, III, IV . Governo do Estado do Rio de Janeiro. SEMADS-FEEMA-SEE (2000). Rio de Janeiro: CEPUERJ.

6. Eigenheer, E. M., Ferreira, J. A., \& Adler, R. R. (2005). Reciclagem: mito e realidade. Rio de Janeiro: In-Fólio.

7. Laera, L. H. N. (2006). Valoração Econômica da Arborização: a valoração dos serviços ambientais para a eficiência e manutenção do recurso ambiental urbano. (Dissertação de Mestrado). Universidade Federal Fluminense, Niterói, RJ, Brasil.

8. Laprovitera (2005). Paisagismo Carioca. Fundação Parques e Jardins. Recuperado de www.rio.rj.gov.br/fpj

9. Lerner, W. (1992). Organização, sistemas e métodos. São Paulo: Atlas.

10. Lorenzi, H. (1992). Árvores brasileiras: manual de identificação e cultivo de plantas arbóreas nativas do Brasil. São Paulo: Plantarum.

11. Lorenzi, H. (2003). Árvores exóticas no Brasil: madeireiras, ornamentais e aromáticas. Nova Odessa, SP: Instituto Plantarum de Estudos da Flora.

12. Madeira, J. M. P. (2005). Administração pública centralizada e descentralizada. Rio de Janeiro: América Jurídica.

13. Moscovici, S. (2007). Natureza-Para Pensar a Ecologia. Rio de Janeiro: Mauad.

14. Prefeitura da Cidade do Rio de Janeiro. (2012). Plano municipal de gestão integrada de resíduos sólidos-PMGIRS da cidade do Rio de Janeiro. Rio de Janeiro: Prefeitura da Cidade do Rio de Janeiro.

15. Sanders, R. A. (1984). Some determinants of urban forest structure. Urban Ecology, 8(1-2), 13-27.

16. Sisinno, C. L. S., \& Oliveira, R. M. D. (2000). Resíduos sólidos, ambiente e saúde: uma visão multidisciplinar. Rio de Janeiro: Fiocruz. 